\title{
Recursos tróficos de Apis mellifera L. (Hymenoptera, Apidae) na região de Morro Azul do Tinguá, Estado do Rio de Janeiro.
}

\author{
CYNTHIA F.P. DA LUZ ${ }^{1,4}$, MARCOS L. THOMÉ ${ }^{2}$ e ORTRUD M. BARTH ${ }^{2,3}$
}

(recebido: 18 de agosto de 2005; aceito: 30 de setembro de 2006)

\begin{abstract}
Trophic resources for Apis mellifera L. (Hymenoptera, Apidae) in the Morro Azul do Tinguá region, Rio de Janeiro state). The original vegetation in the Morro Azul mountain region, northwest of Rio de Janeiro city, was the Atlantic tropical rain forest. Anthropic activities transformed the vegetation into pastureland and patches of the original forest. In addition, there are reforested areas of Pinus, Eucalyptus and others of non native plant species. The aim of the present research was to estimate the contribution of nectar and pollen from each type of vegetation for Apis mellifera bees, using pollen analysis. Eleven monthly collected honey samples and nine samples of pollen loads were obtained in a control-hive and prepared for pollen analysis following the standard European methodology without application of acetolysis. Six honey samples were considered monofloral, as of Baccharis (March), Gochnatia (April and November), Eucalyptus (September and October) and Castanea (August). Three were considered bifloral ones, as of Mimosa scabrella pollen type and Piptadenia (January), Eucalyptus and Eupatorium (June) and Phytolacca and Machaerium pollen type (October). Heterofloral honeys occurred in July (Arecaceae, Eucalyptus and Allophylus) and in December (Anadenanthera, Eupatorium and Eucalyptus). The dominant pollen loads comprised the pollen types of Arecaceae, Baccharis, Castanea, Cecropia, Eucalyptus and Mimosa caesalpiniifolia Benth. The results provided a pollen spectrum that reflected the nectariferous and polliniferous contribution of field vegetation and of introduced plant species in the study region.
\end{abstract}

Key words - Apis mellifera, Brazil, honey, pollen, Rio de Janeiro

RESUMO - (Recursos tróficos de Apis mellifera (Hymenoptera, Apidae) na região de Morro Azul do Tinguá, Estado do Rio de Janeiro). A vegetação original de Morro Azul, região serrana a noroeste da cidade do Rio de Janeiro, era constituída de Mata Atlântica. Sofreu modificações antrópicas e atualmente apresenta áreas de pastagens e manchas de mata remanescente. Ocorrem ainda áreas de reflorestamento com Pinus, Eucalyptus e outras espécies não nativas. O presente trabalho tem como objetivo avaliar, através da análise polínica, a contribuição de cada tipo de vegetação no fornecimento de néctar e pólen para as abelhas Apis mellifera. Onze amostras mensais de mel e nove de cargas de pólen foram obtidas de uma colméia-controle e preparadas para análise palinológica seguindo a metodologia padrão européia, sem aplicação de acetólise. Seis amostras de mel foram consideradas monoflorais, Baccharis (março), Gochnatia (abril e novembro), Eucalyptus (setembro e outubro) e Castanea (agosto). Três foram consideradas biflorais, caracterizadas como mel de Mimosa scabrella tipo polínico e Piptadenia (janeiro), Eucalyptus e Eupatorium (junho) e Phytolacca e Machaerium tipo polínico (outubro). Os méis heteroflorais ocorreram em julho (Arecaceae, Eucalyptus e Allophylus) e dezembro (Anadenanthera, Eupatorium e Eucalyptus). As amostras de cargas de pólen indicaram dominância dos tipos polínicos Arecaceae, Baccharis, Castanea, Cecropia, Eucalyptus e Mimosa caesalpiniifolia Benth. Os resultados forneceram um espectro polínico que refletiu a contribuição nectarífera e polinífera das plantas ruderais e das espécies introduzidas na região.

Palavras-chave - Apis mellifera, Brasil, mel, pólen, Rio de Janeiro

\section{Introdução}

Fator importante para a escolha do local de instalação de um apiário é a composição da flora apícola

\footnotetext{
1. Instituto de Botânica, Seção de Dicotiledôneas, Caixa Postal 3005, 01061-970 São Paulo, Brasil.

2. Instituto de Biologia, Departamento de Botânica, Laboratório de Palinologia, CCS, UFRJ, Cidade Universitária, Ilha do Fundão, Rio de Janeiro, Brasil.

3. Instituto Oswaldo Cruz, Departamento de Virologia, Laboratório de Ultra-estrutura Viral, Fiocruz, Avenida Brasil 4365, 21040-900 Rio de Janeiro, RJ, Brasil.

4. Autor para correspondência: cyluz@yahoo.com.br
}

regional, o que tem implicações no número de colméias e na produção de derivados apícolas que ela poderá comportar (Mello 1989, Howes 1953). Os conhecimentos sobre a flora apícola no Brasil são, em parte, empíricos, limitados a certas regiões do país. A Melissopalinologia visando o reconhecimento de táxons de vegetais através da morfologia do pólen presente em mel e bolotas de grãos de pólen constitui importante instrumento de trabalho. O resultado da análise palinológica quantitativa e qualitativa de amostras de mel ou de bolotas de grãos de pólen constitui seu espectro polínico. Este espectro é relativo à distribuição das plantas produtoras de néctar (melíferas) e às 
produtoras de grãos de pólen (poliníferas) de determinada região geográfica (Barth 1989). Seguindo uma periodicidade mensal, as análises palinológicas desses recursos tróficos fornecem um calendário de florada, valioso para os apicultores.

O hábito alimentar generalista adotado por Apis mellifera L. (Hymenoptera, Apidae), proporciona amplas alternativas alimentares, permitindo que a espécie se adeque às variações na oferta de alimentos, inclusive na presença de competidores (Freitas 1991). A adaptação intrínseca entre abelhas Apis e as espécies de plantas nativas é caracterizada por uma grande variedade de tipos polínicos encontrados nos sedimentos dos méis e das bolotas de grãos de pólen (Barth 1990). Uma revisão regional brasileira sobre estes aspectos foi apresentada por Barth (2004). Com o objetivo de determinar as características melissopalinológicas dos recursos tróficos de Apis mellifera em Morro Azul do Tinguá, distrito do Município de Engenheiro Paulo de Frontin, região serrana a noroeste da cidade do Rio de Janeiro, conduziu-se a presente pesquisa em um apiário situado próximo a um remanescente de mata e a uma área antropizada. Esta região do Estado do Rio de Janeiro ainda não havia sido alvo de pesquisas melissopalinológicas e nem do seu potencial apícola. Área de estudo - A vegetação original de Morro Azul foi completamente modificada por ação antrópica. A floresta original que cobria as encostas norte/nordeste da região foi na sua maior parte removida e ocupada, a partir do século XIX, por plantios de café. Após o declínio econômico do mesmo, os solos foram transformados em pastagens para bovinos, as quais dominam a paisagem até os dias atuais (Ribeiro 1998).

O apiário escolhido, com o propósito de coletar mensalmente amostras de mel e bolotas de grãos de pólen, está localizado no Sítio Coelho Azul (figura 1). Apresenta uma grande área reflorestada, com espécies arbustivas e arbóreas, nativas ou não da região, fruto do esforço do proprietário Sr. Germano Hatzfeld (in memoriam). Entre as espécies replantadas constam diversas Mimosaceae, Fabaceae, Caesalpiniaceae, Bignoniaceae, Arecaceae, Melastomataceae, além de plantas introduzidas como o Pinus sp. ("pinheiro"), Casuarina sp. ("casuarina"), Castanea sp. ("castanheira"), Dombeya wallichii (Lindl.) K. Schum. ("astrapéia-rosa"), Terminalia catappa L. ("amendoeira"), Persea gratissima Gaertn. ("abacateiro") e diversas palmeiras, além de plantas ornamentais. Áreas de pastagem para gado encontram-se ao redor do sítio. Uma vasta plantação de Eucalyptus sp. está localizada a menos de $50 \mathrm{~m}$ do apiário.
Segundo levantamento botânico preliminar da região, realizado por pesquisadores da Universidade Estadual do Rio de Janeiro e pelo Instituto Zoobotânico de Morro Azul do Tinguá (Instituto Zoobotânico de Morro Azul 2005), entre as gramíneas dos pastos ocorrem espécies de Paspalum, Rhynchelytrum e Setaria. Entre as espécies pioneiras (herbáceas, arbustivas e arbóreas), espontâneas nas áreas de pasto e em clareiras da mata remanescente, encontram-se Borreria sp., Cecropia sp., Eupatorium sp., Gochnatia sp., Hyptis sp., Mimosa scabrella Benth. e Vernonia sp. Nas áreas de mata ocorrem as espécies arbóreas Acrocomia aculeata (Jacq.) Lodd., Aegiphila sellowiana Cham., Annona cacans Warm., Apuleia leiocarpa J. F. Macbr., Attalea dubia (Mart.) Burret, Caesalpinia ferrea Mart., Cibistax antisyphilitica Mart., Cupania oblongifolia Mart., Enterolobium contortisiliquum (Vell.) Morong, Euterpe edulis Mart., Inga edulis Mart., Jacaranda puberula Cham., Luehea grandiflora Mart., Piptadenia gonoacantha (Mart.)

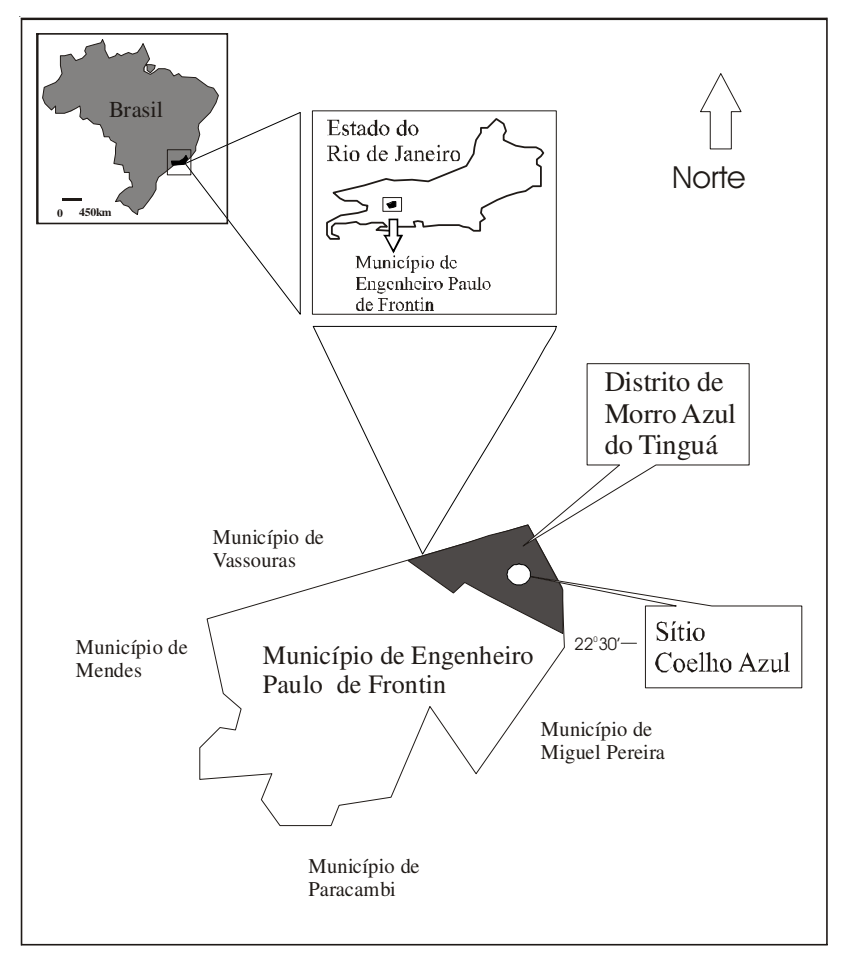

Figura 1. Mapa do Estado do Rio de Janeiro, localizando o Município de Engenheiro Paulo de Frontin, o distrito de Morro Azul do Tinguá e o sítio Coelho Azul (modificado do site www.turisrio.rj.gov.br - acesso em 20/05/2005).

Figure 1. Map of the State of Rio de Janeiro, showing the municipality of Engenheiro Paulo de Frontin, the district of Morro Azul do Tinguá and farm Coelho Azul (modified from the site www.turisrio.rj.gov.br - accessed in 20/05/2005). 
J. F. Macbr., Psidium guajava L., Rapanea ferruginea Mez, Schinus terebinthifolius Raddi, Schizolobium parahyba (Vell.) Blake, Sparattosperma leucanthum (Vell.) K. Schum., Tabebuia chrysotricha (Mart.) Stand1., Trema micrantha (L.) Blume e Zeyheria tuberculosa Bureau.

\section{Material e métodos}

O distrito de Morro Azul do Tinguá está localizado na Serra do Mar, em altitude de 395 m, na latitude de $23^{\circ} 39^{\prime}$ W, a $86 \mathrm{~km}$ da cidade do Rio de Janeiro (figura 1). Apresenta clima quente e úmido, com média de temperatura anual de $22^{\circ} \mathrm{C}$. A taxa de precipitação anual é de $1.480 \mathrm{~mm}$, com chuvas concentradas de dezembro a março e uma estação relativamente seca de julho a setembro, com meses de transição (Ribeiro 1998).

Foi reservado um quadro de melgueira para obtenção de mel e outro de bolotas de grãos de pólen (chamadas também de "pães-das-abelhas" ou grãos de pólen estocados nos alvéolos), exclusivamente para o uso na pesquisa, dentro de uma colméia controle do apiário.

As amostras foram coletadas mensalmente no ano de 2000, chegando-se ao total de 11 amostras de mel e nove de bolotas de grãos de pólen. Não foi possível realizar a coleta de mel no mês de fevereiro, nem as coletas de bolotas de grãos de pólen nos meses de janeiro, fevereiro e maio, ora devido ao tempo chuvoso, ora por dificuldades de acompanhamento pelo apicultor Gilson Ávilla, responsável pelas coletas das amostras.

Os quadros foram substituídos mensalmente e as respectivas amostras eram encaminhadas para o Laboratório de Palinologia, Departamento de Botânica, Universidade Federal do Rio de Janeiro. As bolotas de grãos de pólen eram removidas dos alvéolos com uma pinça e o mel era espremido manualmente.

A preparação polínica das amostras do mel e das bolotas de grãos de pólen seguiu o método padrão europeu (Maurizio \& Louveaux 1965), sem o uso da acetólise. Separou-se $10 \mathrm{~g}$ de mel que foram dissolvidas em $20 \mathrm{~mL}$ de água destilada. Do conjunto de bolotas de grãos de pólen retiradas do favo, separou-se aleatoriamente $5 \mathrm{~g}$ (cerca de 20 bolotas de grãos de pólen), os quais foram macerados em $10 \mathrm{~mL}$ de álcool a $70 \%$, constituindo uma amostra única mensal.

Foram contados, no mínimo, 500 grãos de pólen por amostra de mel e de bolotas. A identificação dos grãos de pólen baseou-se em dados de literatura (Barth 1989, Roubik \& Moreno 1991) e, por comparação, com lâminas da Palinoteca do Laboratório de Palinologia. A determinação das famílias botânicas, a partir da morfologia polínica, não apresentou grande obstáculo, porém em relação ao gênero, isso nem sempre foi possível. Na maioria dos casos não se pôde determinar a espécie, de modo que foi preciso limitar-se ao tipo polínico (tipo morfológico do grão de pólen) (Barth 1989).
$\mathrm{Na}$ avaliação das amostras foram aplicadas as classes de freqüência segundo Zander apud Maurizio \& Louveaux (1965), correspondendo a: $>45 \%$ do total de grãos de pólen contado = pólen dominante (D); de $15 \%$ a $45 \%=$ pólen acessório (A); de 3\% a 15\% = pólen isolado importante (I); e $3 \%=$ pólen isolado ocasional $(\mathrm{O})$. Os valores correspondentes aos grãos de pólen das espécies anemófilas foram subtraídos antes do cálculo das percentagens. Apesar de não contribuir com néctar, seu valor diz respeito à origem fitogeográfica da amostra. Antes da diagnose final, foi levado em consideração a sub e superrepresentação dos táxons botânicos (Barth 1970a, b, c, d, 1989, 1990).

As amostras consideradas como monoflorais foram aquelas cuja contribuição polínica de uma planta foi dominante e as biflorais, quando ambas as contribuições constituíram pólen acessório. Já nos méis heteroflorais não havia nenhuma dominância.

\section{Resultados}

Amostras de mel - Nas onze amostras de mel analisadas, foram identificados 33 tipos polínicos, reconhecendo-se quatro espécies, 23 gêneros e 19 famílias (tabela 1, figuras 2-32).

Os tipos polínicos mais freqüentes nas amostras de mel pertencem às famílias Arecaceae, Asteraceae, Mimosaceae e Myrtaceae (Eucalyptus). O pólen de Eucalyptus ocorreu em todas as amostras de mel analisadas, entretanto, como grão de pólen dominante, somente em setembro e outubro. O pólen de Arecaceae ocorreu em oito amostras, com altos percentuais em maio e julho. Diversos gêneros de Asteraceae ocorreram em todas as amostras, ora contribuindo como pólen dominante (Gochnatia em abril e novembro, Baccharis em março), ora com percentuais mais baixos. A contribuição de Mimosaceae nunca atingiu mais de $45 \%$ do total de uma amostra, mas foi próxima aos $40 \%$ em dezembro (Anadenanthera) e janeiro (Mimosa scabrella e Piptadenia). Castanea contribuiu com néctar somente no mês de agosto, mas, nessa ocasião, atingiu o maior percentual entre os tipos polínicos de todas as amostras de mel (79,2\%).

As seis amostras de mel consideradas monoflorais ocorreram em março (mel de "alecrim" ou "carqueja" - Baccharis), em abril e novembro (mel de "cambará" - Gochnatia), em setembro e outubro (mel de "eucalipto" - Eucalyptus), e em agosto (mel de "castanheira" - Castanea). Três amostras foram consideradas biflorais caracterizadas como mel de Mimosa scabrella ("sensitiva" ou "bracatinga") e Piptadenia ("jacaré") em janeiro, Eucalyptus e Eupatorium ("erva-de-santa-cruz") em junho, 


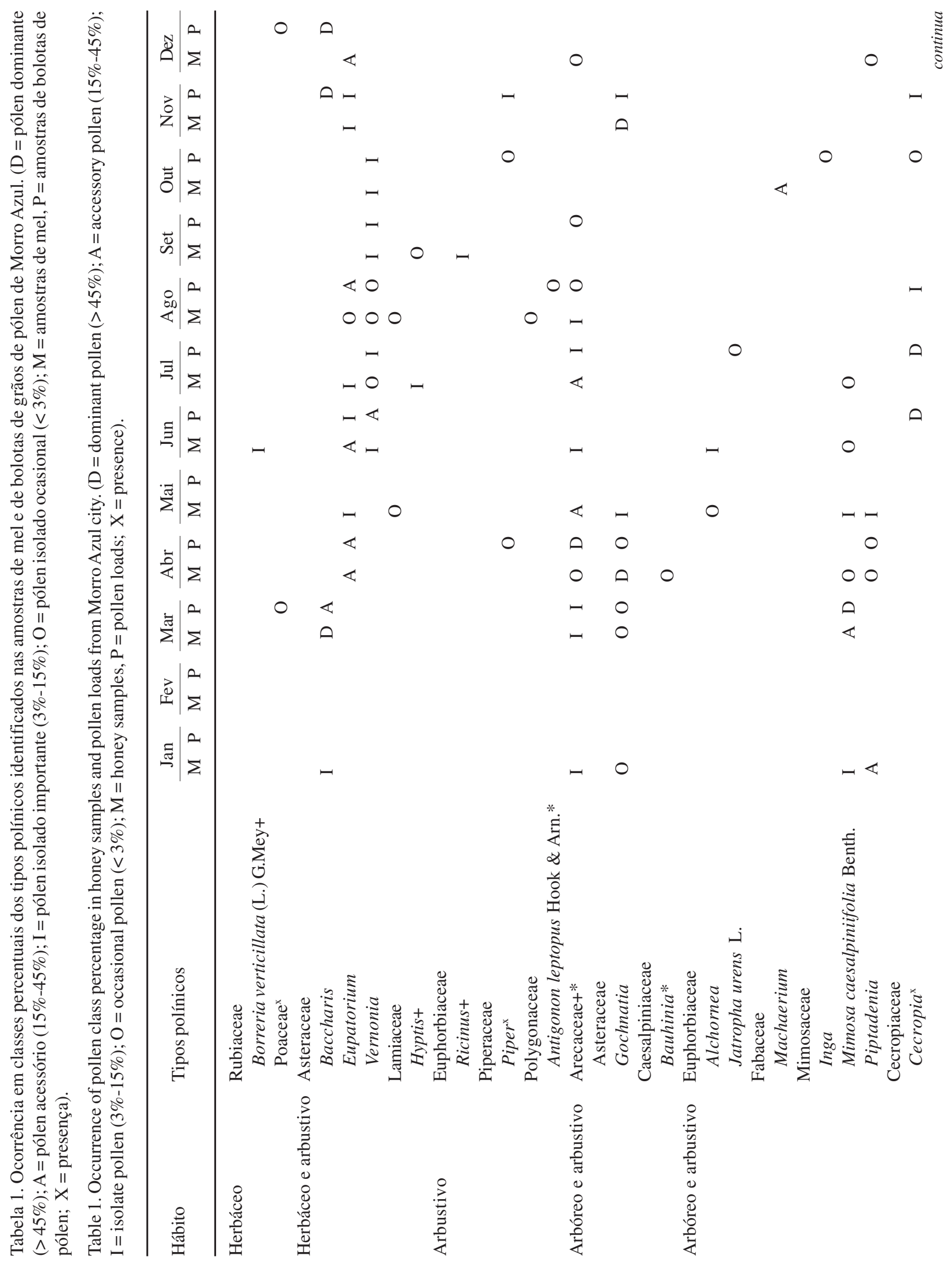


Revista Brasil. Bot., V.30, n.1, p.29-36, jan.-mar. 2007

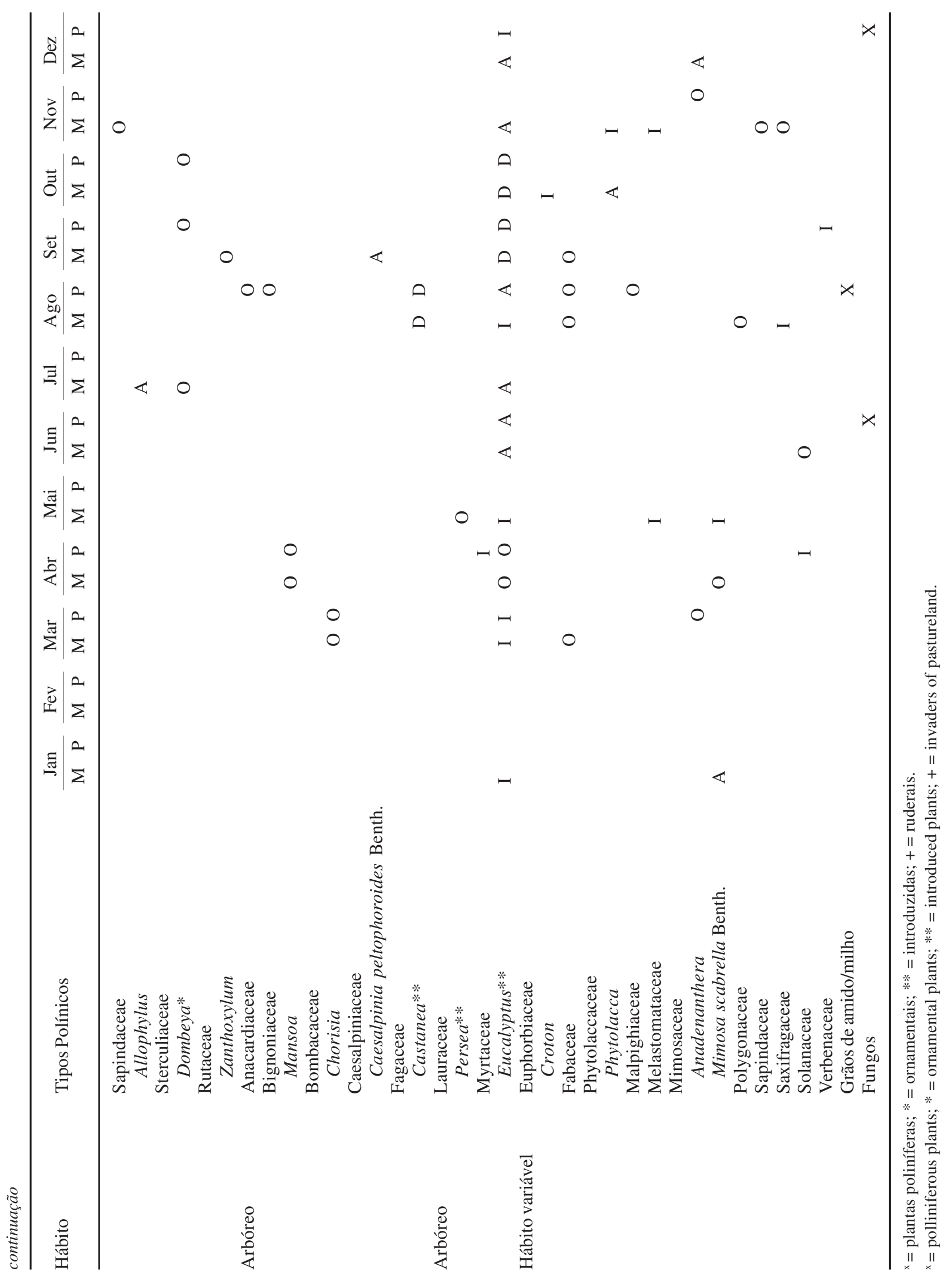


Phytolacca ("carruru-de-pomba") e Machaerium ("jacarandá-roxo") em outubro. Méis heteroflorais apresentando três tipos polínicos na quantidade de pólen acessório (A) ocorreram em julho (Arecaceae, Eucalyptus e Allophylus) e dezembro (Anadenanthera, Eupatorium e Eucalyptus).

Maio foi o mês de maior riqueza em tipos polínicos no mel (11 tipos polínicos), outubro e dezembro, os meses de menor riqueza (cinco tipos polínicos para cada).

Amostras de bolotas de grãos de pólen - Nas nove amostras de bolotas analisadas foram identificados 24 tipos polínicos, representando três espécies, 16 gêneros e 17 famílias (tabela 1, figuras 2-32).

Os tipos polínicos mais freqüentes nas amostras de bolotas de pólen pertencem às famílias Arecaceae, Asteraceae (Baccharis), Mimosaceae (Mimosa caesalpiniifolia), Moraceae (Cecropia) e Myrtaceae (Eucalyptus). O grão de pólen de Eucalyptus ocorreu na maioria das amostras de bolotas analisadas, mas com maior percentual em setembro e outubro (como grão de pólen dominante). Arecaceae ocorreu em cinco amostras, mas somente em abril como pólen dominante. Entre as Mimosaceae, a grande contribuição foi de Mimosa caesalpiniifolia, como pólen dominante em março. Baccharis atingiu o maior percentual entre todos os tipos polínicos das amostras de bolotas (92\%) no mês de dezembro. Cecropia foi observada em cinco amostras, sendo o pólen dominante em junho e julho.

Grande quantidade de pólen de Castanea ocorreu nas bolotas de agosto, atingindo alto percentual entre os tipos polínicos das amostras de bolotas (68\%) nesse mês.

Agosto foi o mês que apresentou a maior riqueza em tipos polínicos nas bolotas de pólen (10 tipos polínicos), dezembro foi o de menor riqueza (três tipos polínicos).

\section{Discussão}

Amostras de mel - O mel produzido em Morro Azul do Tinguá, em grande parte, é proveniente de plantas nativas, ruderais, palmeiras, plantas introduzidas no sítio como obra de paisagismo e da plantação de Eucalyptus.

Com relação à contribuição nectarífera predominante, os méis monofloral e bifloral de Eucalyptus ocorreram sempre próximo às áreas de plantação de espécies desse gênero, sendo que a produção melífera nestes locais chega a ser significativa (Barth 1990). Os méis monoflorais de Baccharis e Gochnatia são produzidos, além da região de estudo, em várias áreas do sudeste do Brasil (Barth 1990, 1996).
A contribuição monofloral de Castanea é exclusiva para o sítio Coelho Azul por se tratar de árvore européia introduzida no sítio pelo seu proprietário. Ela é, essencialmente, uma planta polinífera.

As contribuições nectaríferas representadas por pólen acessório de Caesalpinia peltophoroides ("sibipiruna"), Machaerium e Phytolacca em algumas amostras podem ter tido origem nas espécies arbóreas/ arbustivas da mata remanescente do entorno do sítio Coelho Azul.

Os espectros polínicos observados em algumas amostras de mel de Morro Azul do Tinguá são característicos do Estado do Rio de Janeiro, como foi o caso da associação de Baccharis, Eucalyptus, Hyptis e Ricinus. Diferentes combinações percentuais de Vernonia, Gochnatia, Mimosa caesalpiniifolia, Sapindaceae, Eupatorium, Persea e Croton também ocorrem nos espectros polínicos deste estado (Barth 2004).

Amostras de bolotas de pólen - Com relação às bolotas de grãos de pólen de Apis mellifera, poucos trabalhos foram desenvolvidos para o sudeste do Brasil (Barth 2004). O espectro polínico dominante nas bolotas de Morro Azul analisadas é característico para o Estado do Rio de Janeiro compreendendo Eucalyptus, Arecaceae, Cecropia, Mimosa caesalpiniifolia e Baccharis. A visitação preferencial a Castanea foi observada em agosto e corrobora a predileção de Apis mellifera por essa fonte de pólen como demonstrado por Seijo \& Jato (2001) na Galícia (Espanha). Os resultados palinológicos das bolotas comprovaram também uma visitação preferencial das abelhas a várias plantas da mata remanescente, ruderais e espécies ornamentais introduzidas no sítio.

Os resultados obtidos permitiram estabelecer a contribuição mensal das diferentes espécies botânicas no mel e em bolotas de grãos de pólen, bem como a confecção de um calendário de floradas para a região de Morro Azul.

Os percentuais mensais de cada tipo polínico ora apresentaram concordância entre as amostras de mel e de bolotas, ora discordâncias, sendo que vários deles somente foram vistos ou no mel ou nas bolotas. Estes resultados estão correlacionados às ofertas de néctar e pólen em termos cronológicos, demonstrando que em certas épocas do ano as flores podem ser ou nectaríferas ou poliníferas, enquanto em outras épocas ambos recursos tróficos são ofertados em grande quantidade. Os resultados das análises palinológicas, tanto do mel quanto das bolotas, forneceram um espectro polínico que reflete, em grande parte, a contribuição nectarífera 

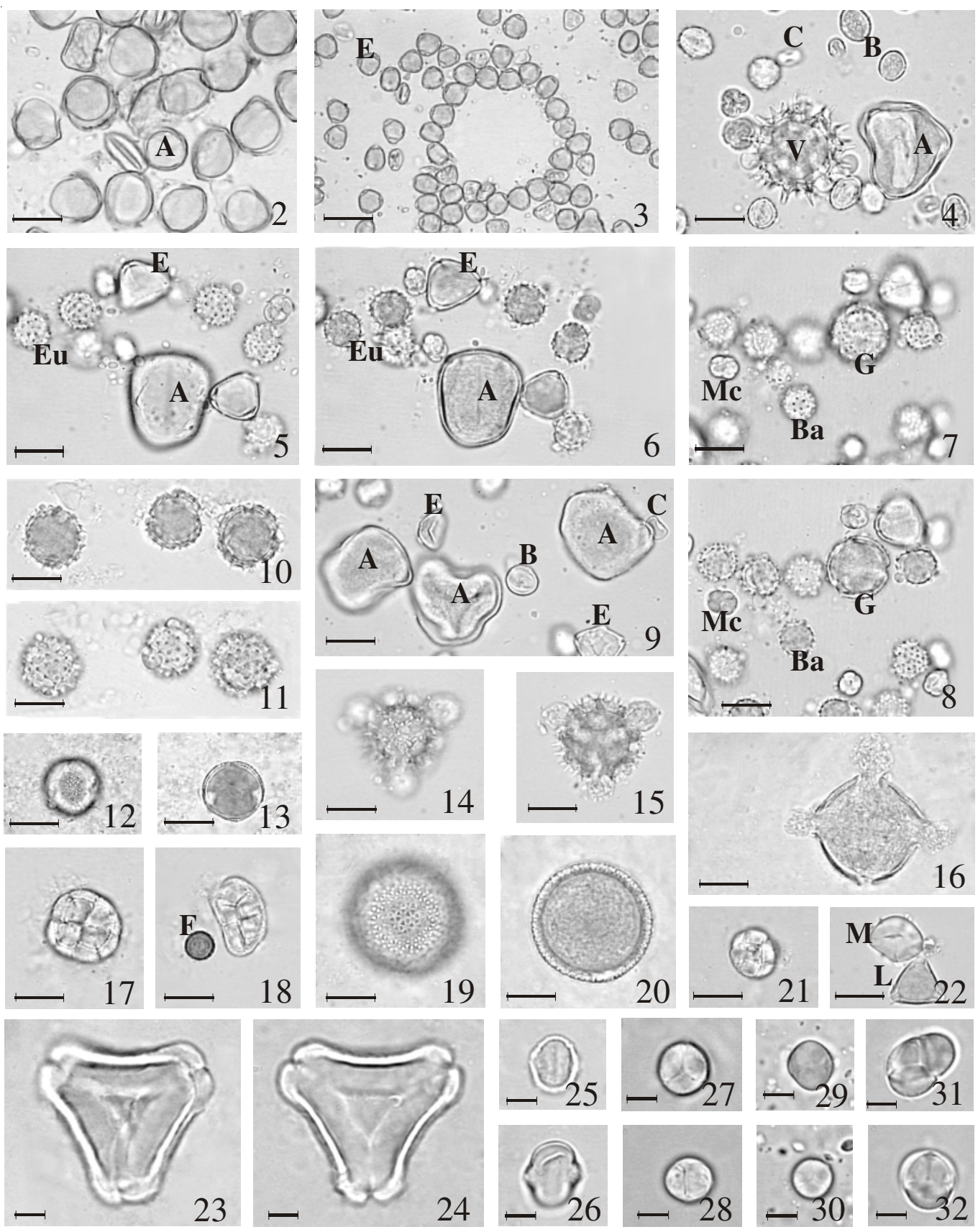

Figuras 2-32. Fotomicrografias de grãos de pólen em amostras de mel e bolotas de pólen. 2. Amostra de bolota de pólen de Arecaceae (A). 3. Amostra de bolota de pólen de Eucalyptus (E). 4-9. Amostras de mel com grãos de pólen de Arecaceae (A), Baccharis (Ba), Castanea (B), Cecropia (C), Eucalyptus (E), Eupatorium (Eu), Gochnatia (G), Mimosa caesalpiniifolia (Mc) e Vernonia (V). 10-11. Eupatorium. 12-13. Caesalpinia peltophoroides. 14-15. Vernonia com intina proeminente nas aberturas. 16. Portulacca. 17-18. Anadenanthera colubrina e esporo de fungo (F). 19-20. Croton. 21. Piptadenia communis. 22. Allophylus (L) e grão de amido (M). 23-24. Eucalyptus. 25-26. Cecropia. 27-30. Mimosa scabrella. 31-32. Mimosa verrucosa. Barras = $20 \mu \mathrm{m}$ (2-22), $5 \mu \mathrm{m}(23-32)$.

Figures 2-32. L.M of pollen in honey and pollen load samples. 2. Pollen load sample of Arecaceae (A). 3. Pollen load sample of Eucalyptus (E). 4-9. Honey samples with pollen of Arecaceae (A), Baccharis (Ba), Castanea (B), Cecropia (C), Eucalyptus (E), Eupatorium (Eu), Gochnatia (G), Mimosa caesalpiniifolia (Mc) and Vernonia (V). 10-11. Eupatorium. 12-13. Caesalpinia peltophoroides. 14-15. Vernonia with prominent intina in the colpus. 16. Portulacca. 17-18. Anadenanthera colubrina and fungus spore (F). 19-20. Croton. 21. Piptadenia communis. 22. Allophylus (L) and starch grain (M). 23-24. Eucalyptus. 25-26. Cecropia. 27-30. Mimosa scabrella. 31-32. Mimosa verrucosa. Bars = $20 \mu \mathrm{m}$ (2-22), 5 um (23-32). 
e polínica das plantas da mata remanescente, ruderais e das espécies introduzidas na região.

Tipos polínicos de espécies heliófitas encontradas nas amostras como Cecropia, Ricinus, Croton, Poaceae e diversas Asteraceae, entre outros, indicam a colonização de plantas em clareiras na mata, o que reflete a situação tanto do apiário Coelho Azul quanto do entorno do sítio.

Uma menor contribuição de espécies arbóreas e arbustivas nativas ocorreu provavelmente devido à facilidade de obtenção de néctar e pólen junto ao próprio apiário, assim como por causa do espaçamento natural das espécies florestais e pela maior distância do apiário em relação à mata remanescente. $\mathrm{O}$ maior potencial da área do sítio Coelho Azul na produção de mel monofloral refere-se às plantas arbustivas e arbóreas de Baccharis, Castanea, Eucalyptus e Gochnatia cobrindo os meses de março-abril e de agosto-novembro. Já quanto à produção de pólen, destacam-se as plantas de Arecaceae, Baccharis, Castanea, Cecropia, Eucalyptus e Mimosa scabrella, cobrindo os meses de março-abril e de junho-dezembro. O mês mais fraco na produção de mel e pólen (com exclusão de fevereiro, sem coleta) foi maio, sustentado pela contribuição de Arecaceae. A diversidade e utilização das plantas nativas pelas abelhas foi evidente o que ressalta a importância da preservação da vegetação nativa para a sobrevivência das colméias durante os tempos de escassez de oferta dos recursos florais das plantas introduzidas como, por exemplo, Piptadenia e Mimosa scabrella em janeiro.

Os resultados demonstraram que o desenvolvimento da apicultura em Morro Azul do Tinguá, especialmente no entorno do sítio Coelho Azul, é bastante promissor e que a região pode comportar grande número de colméias da abelha Apis mellifera.

Agradecimentos - Ao Sr. Germano Hatzfeld (in memoriam) pelo incentivo e apoio à esta pesquisa e ao apicultor Sr. Gilson Ávilla pela ajuda nas coletas do mel e de bolotas de pólen. Ao Departamento de Botânica da Universidade Federal do Rio de Janeiro pelo apoio logístico. Ao CNPq pela bolsa de produtividade para a terceira autora.

\section{Referências bibliográficas}

BARTH, O.M. 1970a. Análise microscópica de algumas amostras de mel. 1. Pólen dominante. Anais da Academia Brasileira de Ciência 42:351-366.

BARTH, O.M. 1970b. Análise microscópica de algumas amostras de mel. 2. Pólen acessório. Anais da Academia Brasileira de Ciências 42:571-590.

BARTH, O.M. 1970c. Análise microscópica de algumas amostras de mel. 3. Pólen isolado. Anais da Academia Brasileira de Ciências 42:747-772.

BARTH, O.M. 1970d. Análise microscópica de algumas amostras de mel. 4. Espectro polínico de algumas amostras de mel do Estado do Rio de Janeiro. Revista Brasileira de Biologia 30:575-582.

BARTH, O.M. 1989. O pólen no mel brasileiro. Editora Luxor, Rio de Janeiro.

BARTH, O.M. 1990. Pollen in monofloral honeys from Brazil. Journal of Apicultural Research 29:89-94.

BARTH, O.M. 1996. Monofloral and wild flower honey pollen spectra in Brazil. Ciência e Cultura 48:163-165.

BARTH, O.M. 2004. Melissopalynology in Brazil: a review of pollen analysis of honeys, própolis and pollen loads of bees. Scientia Agricola 61:342-350.

FREITAS, B.M. 1991. Potencial da caatinga para produção de pólen e néctar para a exploração apícola. Dissertação de mestrado, Universidade Federal do Ceará, Fortaleza.

HOWES, F.N. 1953. Plantas melíferas. Editora Reverte, Barcelona.

INSTITUTO ZOOBOTÂNICO DE MORRO AZUL. http:// www.izma.org.br (acesso em 15/06/2005).

MAURIZIO, A. \& LOUVEAUX, J. 1965. Pollens de plantes mellifères d'Europe. Union des groupements apicoles français, Paris.

MELLO, N.B. 1989. Guia prático do apicultor. Editora Ground, São Paulo.

RIBEIRO, L.S. 1998. Município de Engenheiro Paulo de Frontin, um pouco de sua história e da sua gente. Editora Sólon Ribeiro, Rio de Janeiro.

ROUBIK, D.W. \& MORENO, J.E.P. 1991. Pollen and spores of Barro Colorado Island. Missouri Botanical Garden. Monographs in Systematics Botany 36:1-268.

SEIJO, M.C. \& JATO, M.V. 2001. Distribution of Castanea pollen in Galician honeys (NW Spain). Aerobiologia 17: 255-259. 